\title{
Challenges in the management of severe allergic asthma in the elderly
}

\author{
This article was published in the following Dove Press journal: \\ Journal of Asthma and Allergy \\ 17 March 2016 \\ Number of times this article has been viewed
}

\author{
Ayse Bilge Ozturk' \\ Sinem Iliaz ${ }^{2}$ \\ 'Department of Allergy and \\ Immunology, ${ }^{2}$ Department of \\ Pulmonary Medicine, Koç University \\ Hospital, Istanbul, Turkey
}

\begin{abstract}
Little is known about the features of asthma and allergy in the elderly. A significant number of elderly patients with asthma have uncontrolled and severe asthma. This review aims to provide an analysis of the literature on the assessment and phenotype of severe allergic asthma in the elderly. Gaps and pitfalls in diagnostic and therapeutic approaches, as well as management of severe allergic asthma in the elderly, are also discussed.
\end{abstract}

Keywords: allergy, asthma, elderly, severe, chronic obstructive pulmonary disease, atopy

\section{Introduction}

Asthma is a common chronic disease that affects $\approx 300$ million people worldwide. ${ }^{1}$ Prevalence of asthma among countries varies from $1 \%$ to $28 \%$ and affects people of all races and age groups. ${ }^{1}$ Adult-onset or late-onset asthma is considered if asthma symptoms appear in adulthood. ${ }^{2}$ Age at diagnosis can vary from 12 years to $\geq 65$ years. $^{3,4}$ Recent epidemiologic studies have shown that asthma is prevalent in the elderly $(4.5 \%-12.7 \%) .{ }^{5}$ One study demonstrated the rate of newly diagnosed asthma in patients aged $\geq 65$ years to be $0.1 \%$ per year. ${ }^{6}$ The number of people aged $\geq 60$ years is growing rapidly in developed countries. By 2030, it is estimated that this group will be $\approx 20 \%$ of the total population. ${ }^{7}$ This expected increase in the prevalence of asthma in the elderly has led to increased interest in the phenotyping of asthma in this population based on severity, age at diagnosis, spectrum of symptoms, treatment response, triggering factors, and level and type of inflammation.

Some data suggest that asthma in older adults is phenotypically different from that in younger patients. ${ }^{1,8}$ That is, a significant number of older people with asthma have uncontrolled and severe asthma, which leads to increased morbidity and mortality. ${ }^{1}$ Several factors in older patients with asthma contribute to the risk of uncontrolled disease: a low level of education; poor memory and coordination; and hearing, visual, and neuromuscular difficulties in learning inhaler-use methods and asthma selfmanagement plans. ${ }^{8}$ Older patients with asthma also have an increased likelihood of comorbidities and polypharmacy, which can lead to worsening of asthma. ${ }^{8}$

Asthma management in the elderly follows the same steps as that for younger adults. ${ }^{1}$ Nevertheless, asthma in the elderly is being underdiagnosed and undertreated. ${ }^{1}$ Usually, the term older adults is applied to persons aged $\geq 65$ years, but the definition of older persons in the asthma literature is not homogeneous. Many reports on asthma in the elderly are findings from general surveys in adults and have not focused primarily on asthma characteristics in the elderly. Hence, more studies are needed to
Correspondence:Ayse Bilge Ozturk Department of Allergy and Immunology, Koç University Hospital, Davutpasa Street No 4, Topkapi, Istanbul 34365, Turkey $\mathrm{Tel}+908502508250$

Fax +9021231I 2274

Email aysebilgeozturk@yahoo.com
Journal of Asthma and Allergy 2016:9 55-63

(c) (1) (8) ( 2016 0zturk and lliaz. This work is published and licensed by Dove Medical Press Limited. The full terms of this license are avallable at https://www.dovepres.com/ cc. work you hereby accept the Terms. Non-commercial uses of the work are permitted without any further permisision from Dove Medical Press Limited, provided the work is property attributed. For permission for commercial use of this work, please see paragraphs 4.2 and 5 of our Terms (https://www.doveperess.com/terms.php).
Dovepress

http://dx.doi.org/10.21477|]AA.S85420
5 
ascertain the prevalence and features of asthma and allergy in the elderly.

This review aims to provide analyses of the literature on the assessment and phenotype of severe allergic asthma in the elderly. Gaps and pitfalls in diagnostic and therapeutic approaches, as well as management of severe allergic asthma in the elderly, are also discussed.

\section{Phenotype of allergic asthma in the elderly}

Asthma in the elderly is a mixture of childhood-onset and adult-onset disease..$^{9}$ Asthma may persist from childhood or start in adult life. Hence, elderly patients with asthma can be grouped as patients with long-standing asthma or patients with late-onset disease..$^{9}$ Atopy is more frequent in early-onset asthma than in late-onset asthma. ${ }^{9}$ Atopy increases the risk of asthma in children and younger adults ${ }^{9}$ and may also increase the risk of asthma in the elderly. Recent studies have suggested that allergic sensitization in patients with asthma aged $\geq 55$ years might be more common than reported. ${ }^{10}$ Busse et $\mathrm{al}^{11}$ found that sensitization to indoor allergens was strongly associated with asthma in elderly patients. Sensitization to house dust mites, mold, and cockroaches can increase the prevalence of asthma in the elderly. ${ }^{12,13}$ Studies also suggest that sensitization and exposure to pollen allergens result in persistent and severe asthma in adults. ${ }^{14}$ Parietaria is more important than Olea and Gramineae as a risk factor for the development of nonspecific bronchial hyperresponsiveness. ${ }^{14}$ Celikel et $\mathrm{al}^{15}$ analyzed the records of 922 patients diagnosed with seasonal allergic rhinitis retrospectively to determine the risk factors for asthma in adults. They divided patients with seasonal allergic rhinitis into four groups: 1) no sensitization, 2) monopollen sensitization, 3) polypollen sensitization, and 4) mite sensitization. Compared with the polypollen sensitization group, groups with no sensitization and mite sensitization had a higher risk of asthma, whereas the monopollen sensitization group was unlikely to have any other allergic disease (including asthma). ${ }^{15}$ Data support an association between pollen sensitization and adult-onset asthma, but sensitization to pollen is not significantly associated with asthma symptoms in the elderly. ${ }^{12,13}$ Recently, we showed that the prevalence of atopy was $21 \%$ in an elderly population with asthma; these patients were most commonly sensitized to Dermatophagoides pteronyssinus (44.4\%), followed by Blattella germanica (27.7\%), Aspergillus fumigatus (27.7\%), Dermatophagoides farinae (22.2\%), and a grass mix (11.1\%). ${ }^{16}$ Our results were similar to those of Busse et al, ${ }^{11}$ who found that sensitization to house dust mites, mold, and cockroaches was an important factor in elderly patients with asthma. Of these patients, $44 \%$ had mild, $41 \%$ had moderate, and $5 \%$ had severe persistent asthma. In all, $93.9 \%$ of patients had late-onset disease (age $>18$ years). ${ }^{16}$ Atopy seems to be closely linked with late-onset asthma as well as long-standing asthma. Wolfe et $\mathrm{al}^{17}$ found that an atopic condition (defined as rhinitis, eczema, or positive skin reactions to rye grass or house dust mite in childhood) increased the risk of more severe asthma in adult life.

Presentation of allergic asthma in the elderly is not different to that in younger patients. Ozyigit Pur et $\mathrm{al}^{18}$ found that older individuals with allergic asthma had similar clinical and laboratory characteristics to those of a younger age group. In that report, asthma severity was not different between older and younger patients with allergic asthma. However, older patients with asthma had worse control of asthma and lower values for forced expiratory volume in 1 second $\left(\mathrm{FEV}_{1}\right)$ and forced vital capacity when compared with younger patients with allergic asthma. ${ }^{18} \mathrm{~A}$ study by Inoue et $\mathrm{al}^{19}$ elicited similar results to those by Ozyigit Pur et al, ${ }^{18}$ with no significant differences in blood or sputum cells, exhaled nitric oxide, or airway responsiveness to methacholine between older and younger patients with asthma. However, based on analyses of spirometry, computed tomography, and impulse oscillation, elderly patients with asthma had greater involvement of small and large airways than nonelderly patients with asthma. ${ }^{19}$

Clinical characteristics of severe asthma in the elderly have been reported to be complex and considerably distinct. In particular, late-onset asthma appears to be more severe and less atopic in nature. ${ }^{20}$ In the Cardiovascular Health Study, ${ }^{21}$ respiratory symptoms in patients with late-onset asthma (cough, phlegm, wheezing, and dyspnea) were more prevalent compared with patients whose asthma began before the age of 20 years. Elderly individuals with asthma reported that the most common trigger was a viral infection or animal allergies.

Patients with long-standing asthma have worse and more frequent respiratory symptoms, an increased number of hospitalizations and emergency medical interventions, and lower parameters of lung function. ${ }^{22}$ Park et $\mathrm{al}^{23}$ established a prospective, observational cohort of elderly Korean patients with asthma to identify elderly patients with asthma with distinct clinical phenotypes. Four clusters of elderly patients with asthma were identified: 1) long duration of symptoms and marked obstruction of airways, 2) female dominance and normal lung function, 3) male dominance for smoking and reduced lung function, and 4) high body mass index and borderline lung function. Prevalence of atopy 
among the four clusters was $15.6 \%-26.4 \%$. Cluster 3 (male dominance for smoking and reduced lung function) had a significantly higher prevalence of atopy. Cluster 1 had a significantly longer duration of symptoms, severe obstruction of airways, and a higher number of exacerbations. Park et $\mathrm{al}^{23}$ found long duration of symptoms and smoking to be related to reduced lung function in elderly patients with asthma even after bronchodilator inhalation.

\section{Management challenges}

Many patients with adult-onset asthma have a poor prognosis, with a faster decline in lung function and more severe, persistent limitation of airflow. ${ }^{2}$ Compared to younger adults, a significant number of older individuals with asthma have poorly controlled asthma, which can lead to increased numbers of prescriptions of asthma medications, hospitalizations, and deaths. ${ }^{4}$ If asthma develops at an advanced age, symptoms are much like those among younger adults. However, greater amounts of medication are needed to maintain asthma control in elderly populations because they may be more likely to have respiratory failure with other diseases, such as chronic obstructive pulmonary disease (COPD) and congestive heart failure. Tsai et $\mathrm{al}^{24}$ published the results of analyses of a large, USA-wide database for emergencydepartment visits. They found that of those who visited the emergency department for asthma problems, those aged $\geq 55$ years had a higher prevalence of hospitalization and near-fatal asthma events, longer duration of hospital stay, and higher overall mortality than adults aged $18-54.9$ years. Talreja and Baptist ${ }^{25}$ compared younger patients with asthma with older patients with asthma and found that the latter were more likely to be obese, to be smokers, and to have worse control of asthma. As stated earlier, several factors in older patients with asthma contribute to the risk of uncontrolled disease: a low level of education; poor memory and coordination; and hearing, visual, and neuromuscular difficulties in learning inhaler-use methods and asthma self-management plans. Older patients with asthma also receive several types of medications for different health problems that can react with asthma treatments. ${ }^{7}$

Asthma management in the elderly is beset with problems. The goal of asthma therapy is to reduce the frequency and severity of symptoms and exacerbations, maintain normal levels of activity, and achieve optimal lung function. Management of severe allergic asthma in the elderly follows the same steps as that in younger adults to achieve these goals. ${ }^{1}$ The European Respiratory Society and American Thoracic Society Task Force on severe asthma ${ }^{26}$ has defined the following three main steps in the management of severe allergic asthma in the elderly.

\section{Step I: definition \\ Confirmation of the diagnosis}

Classic symptoms of asthma in the elderly are similar to those of younger individuals with asthma. ${ }^{27}$ Most patients complain of episodic wheezing, dyspnea, and a feeling of chest tightness. These symptoms are often worse at night and upon exertion in younger patients with asthma. ${ }^{27}$ Asthma symptoms can be triggered by infections of the respiratory tract, aeroallergens, irritants, and the medications commonly used by this patient population (aspirin, nonsteroidal antiinflammatory agents, angiotensin-converting enzyme inhibitors, and beta-blockers). ${ }^{27}$ The diagnosis of asthma may be more difficult in the elderly because of the high prevalence of other disorders that can have similar symptoms (congestive heart failure, emphysema, COPD, chronic aspiration, gastroesophageal reflux disease (GERD), and tracheobronchial tumors). ${ }^{27,28}$ Comorbidities and the psychosocial effects of aging may also affect the diagnosis profoundly. Differentiation of chronic asthma from COPD can be very challenging, and in some patients, asthma cannot be distinguished from COPD with the available diagnostic tests. COPD management may have similarities with that of asthma. ${ }^{27}$ In elderly patients (as for younger adults), careful history-taking is necessary to identify symptoms and triggers. Physical examination should include examination of upper airway and chest auscultation, and alternative causes of respiratory symptoms should be considered and investigated fully, including use of pre- and postbronchodilator spirometry. ${ }^{1}$ Further diagnostic tests are needed to exclude other conditions or comorbidities (eg, parenchymal lung disease, COPD, GERD, sleep apnea, and congestive heart failure). ${ }^{1}$

Differentiation between severe asthma and mild asthma Severe asthma can be defined as asthma that requires treatment with high-dose inhaled corticosteroids and a second controller (and/or systemic corticosteroids) to prevent it from becoming uncontrolled, or which remains uncontrolled despite such therapy. ${ }^{26}$ Severe asthma involves almostcontinuous symptoms, frequent exacerbations, frequent night-time awakenings, limited activities, peak expiratory flow or $\mathrm{FEV}_{1}$ baseline $<60 \%$ predicted, and peak expiratory flow variation of $20 \%-30 \%$. Therefore, this definition includes patients at steps 4 and 5 of guidelines set by the Global Initiative for Asthma (GINA). ${ }^{1}$ Severe asthma in the elderly can be accompanied by the presence or absence of 
a significant irreversible component of obstruction. ${ }^{29}$ There is considerable variation in the duration and severity of asthma, and many of these patients have severe, irreversible obstruction unrelated to asthma duration. ${ }^{29}$ The degree of irreversible obstruction is unrelated to pack-years of cigarette smoking, suggesting that there are additional causes. Coexisting COPD and bronchiectasis with segmental pulmonary fibrosis can also cause irreversible obstruction in cases with severe asthma. ${ }^{29}$

\section{Determination of whether severe asthma is controlled or uncontrolled}

Any one of the following four criteria can be used to define uncontrolled asthma: poor control of symptoms (ie, asthma control questionnaire $>1.5$ consistently or asthma control test $<20$ ); frequent severe exacerbations (defined as $\geq 2$ bursts of systemic corticosteroids [ $>3$ days each] in the previous year); serious exacerbations (defined as at least one hospitalization stay in the intensive care unit, or mechanical ventilation in the previous year); and airflow limitation (ie, $\mathrm{FEV}_{1}<80 \%$ predicted after withholding of short- and long-acting bronchodilators). ${ }^{26}$ A significant number of older people with asthma have uncontrolled and severe asthma, which can lead to increased morbidity and mortality. ${ }^{1}$ Compared to young adults with asthma, elderly adults with asthma have worse short-term (symptoms within the previous week, day-and-night symptoms during the previous 30 days, and corticosteroid use in the previous 3 months) and long-term (asthma attack, emergency-department visit, hospitalization, and activity limitations in previous year) control. ${ }^{24}$ Recently, we showed that $52 \%$ of elderly patients had uncontrolled asthma. ${ }^{16}$ In a recent multicenter observational study, $39 \%$ of elderly patients with asthma had uncontrolled asthma despite receiving high-level GINA-based therapy (steps 3-4). ${ }^{30}$

\section{Step 2: patient evaluation}

\section{Assessment of contributory factors}

If the diagnosis of asthma has been confirmed, coexisting conditions must be determined and addressed. Adherence to asthma medications (as well as poor methods of inhalation of medications) presents problems in all age groups. ${ }^{1}$ However, it has been suggested that older people are less likely to adhere to medications and to use their inhaler devices appropriately when compared to younger adults. ${ }^{16,18,31}$ Detection of poor adherence can be challenging. Yap et $\mathrm{al}^{32}$ reviewed the barriers affecting medication adherence in older adults. They categorized the barriers into five main factors: patient, medication, physician, system-based, and other (Figure 1).
The attending physician should focus and address all factors affecting medication adherence in older adults. Improper use of inhaler devices in older people is very common. Recently, we showed that $52 \%$ of patients had uncontrolled asthma and, of these elderly patients with asthma, only $48.7 \%$ used their inhaler devices properly. ${ }^{16}$ Arthritis of the hands, tremors, low inspiratory flow rates, and problems in hearing, seeing, and neuromuscular coordination can result in difficulties with inhaler manipulation. ${ }^{31}$ Atopy and allergy, rhinosinusitis, nasal polyps, GERD, obesity, concurrent smoking, anxiety, and depression are important coexisting conditions that may contribute to asthma severity. ${ }^{25}$ In adults, chronic disease in the upper airways (particularly sinusitis) is very often associated with poor outcomes. In the Severe Asthma Research Program study, ${ }^{33} 54 \%$ of patients with severe asthma had a history of sinusitis. Cluster analyses in the Severe Asthma Research Program study showed that sinus disease was significantly more frequent in patients with a severe asthma phenotype in the oldest patients. ${ }^{34}$

\section{Interactions among the effects of aging, asthma, and coexisting disease}

Elderly patients with asthma frequently have coexisting diseases. ${ }^{5}$ Coexisting disease and disease-related treatments should be considered in the diagnosis and management of asthma. Elderly individuals with asthma have an increased prevalence of respiratory diseases, such as chronic bronchitis, COPD, chronic sinusitis as well as stomach ulcers, cardiovascular disease, osteoporosis, diabetes mellitus, depression, and cancer when compared to younger patients with asthma. ${ }^{35}$ Individuals with severe asthma have a higher prevalence of sinusitis, GERD, hypersensitivity to nonsteroidal anti-inflammatory drugs, pneumonia, obstructive sleep apnea syndrome, recurrent respiratory infections, and neuropsychological problems when compared to patients with nonsevere asthma. ${ }^{26,35} \mathrm{~A}$ recent study reported that elderly patients with asthma had a significantly higher mean number of chronic comorbidities (8.4) than those in younger patients (3.4). ${ }^{35}$ In the elderly, differentiating age-related normal physiological and neuropsychological changes from asthma-related abnormal changes can be very difficult. Normal aging-associated changes in lung structure probably worsen asthma symptoms. ${ }^{36}$ Such changes sometimes make it difficult to distinguish clearly between asthma and COPD, especially in patients who have smoked tobacco. Initially, asthma symptoms may be masked by or misdiagnosed as other disorders, such as congestive heart failure. ${ }^{36}$ In particular, elderly patients are exposed to the negative 


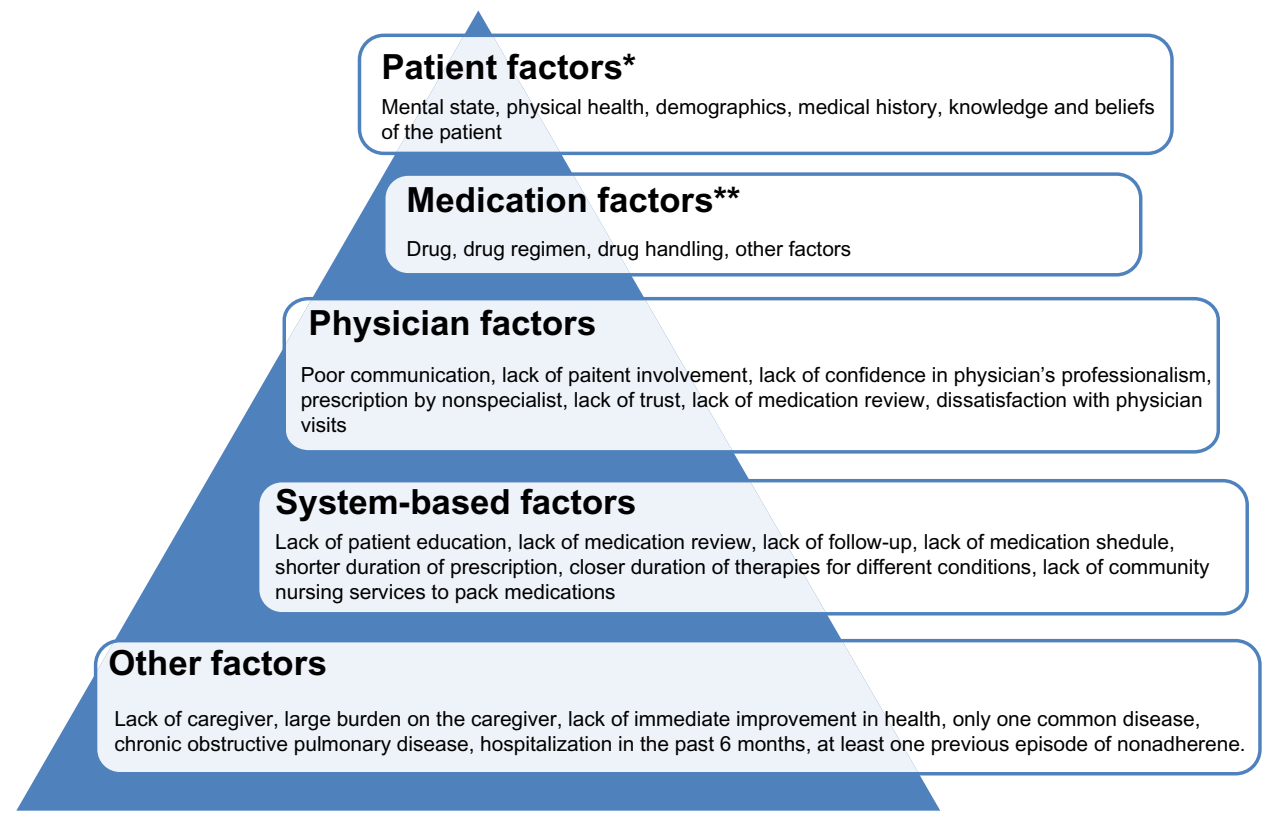

Figure I Factors effecting medication adherence.

Notes: *Mental state factors are depression, low cognitive function, poor memory, poor executive function, anxiety, and sleep disturbances. Factors classified under physical health are poor dexterity, body mass index $>25.0 \mathrm{~kg} / \mathrm{m}^{2}$, poor physical function, impaired hearing, and low self-rated health. Factors classified under demographics are age, sex, education level, marital status, language spoken, culture, and ethnicity. Behavioral factors comprise neurotic personality, nonadherence to nonpharmacologic therapies, use of complementary and alternative medications, lack of concurrent use of over-the-counter medicines, problems in drinking, low self-care, resisting care, poor independence when taking medications, and lack of interpersonal relationships. Factors classified under knowledge or beliefs comprise beliefs about medications, lack of a threatening view of illness, higher perceived illness burden, lack of perceived benefit of medications, knowledge of chronicity of illness and consequences of illness, and lack of knowledge of the condition. Other factors comprise living in your own home, poor literacy on health, lack of medication knowledge, and misunderstanding of verbal instructions. **Formulation, packaging, types of medications, generic substitution, and drug storage issues are classified under drug factors. Drug regimen factors are multiple medications, changes to the regimen, and complex dosing regimens. Lack of use of medication boxes, need to split tablets, and difficulty in opening childproof containers are categorized under drug handling factors. Other factors include the cost and lack of insurance coverage, adverse drug reactions, drug interactions, poor labeling instructions, short-term medications, and lack of understanding of immediate consequences of missed doses. Data from Goeman and Douglas. ${ }^{31}$

effects of polypharmacy, and some treatments taken for coexisting diseases may worsen asthma control by inducing bronchospasm. ${ }^{36}$ It is important to ask which other medications elderly asthma patients are using. Clinicians need to be aware of the potential for interactions among the effects of aging, asthma, coexisting diseases, and various medications in elderly patients. Patient education and asthma management plans for elderly patients should take into account all the following possible conditions: loss of coordination and muscle strength, hearing and visual difficulties, sleep disturbances, impaired cognitive function, neuropsychological diseases, and depression.

\section{Special groups}

Asthma in patients with neuropsychological diseases Memory changes are common in the elderly. A loss of neurons in certain areas of the brain can increase reaction times and reduce the ability to respond to multiple complex stimuli in the elderly. ${ }^{36}$ In addition, pathologic conditions, such as stroke, dementia, anemia, electrolyte imbalance, thyroid dysfunction, and poor cardiac function, are more frequent in the elderly. ${ }^{36}$ All these contributory factors can lead to confusion and affect the ability to learn and use new information. ${ }^{36}$ The most common psychoneurological problems are depression and dementia in elderly asthmatic patients. ${ }^{36}$ Studies have suggested an association between asthma and dementia, but the results are inconsistent. ${ }^{37}$ Untreated asthma could be also associated with declining cognitive function. A recent study by Bozek and Jarzab ${ }^{38}$ reported that, after 1 year of antiasthmatic treatment, some cognitive and instrumental activities increased significantly in asthma patients with Alzheimer's disease. However, $\approx 10 \%$ of elderly patients are mentally debilitated, ${ }^{36}$ and getting asthma symptoms under control in such patients is very difficult. Clinicians often face challenges in maintaining asthma control in elderly patients with mental problems. Many of these patients with dementia do not present with typical symptoms (eg, breathlessness and cough). Mental status and neuropsychiatric disorders can cause aspiration, which can exacerbate asthma symptoms. ${ }^{36}$ These patients are often hypoxic, and most of them cannot take medication of any type by themselves. Family members, friends, or special nurse care for an impaired elderly person may be needed. Education and support programs for caregivers 
of patients with dementia could be effective in reducing treatment problems and improving the management of asthma and dementia. Nebulizers can also replace inhalers in such patients.

Prevalence of concomitant depression in elderly patients with asthma is $17 \%$. Depression can also be caused by commonly used medications in the elderly, such as corticosteroids, antihypertensive agents, and anti-Parkinsonian drugs. ${ }^{34}$ The association among depression, psychiatric disorders, and asthma is stronger in females than in males. ${ }^{39}$ There is a close relationship with asthma, mortality, and depression. ${ }^{36}$ Depression may also reduce compliance with treatment plans and patient motivation to engage in normal activities. ${ }^{36}$ Hence, depression should be treated for the maintenance of asthma control in these patients. Several studies have reported on various aspects of the coexistence of asthma, multiple sclerosis, and Parkinson's disease, but the results are contradictory. ${ }^{40,41}$

\section{Asthma-COPD overlap syndrome (ACOS)}

ACOS is the definition for a condition in which a person has the clinical features of asthma and COPD. ${ }^{1,42}$ ACOS is common among elderly asthmatic people with a history of smoking or long-term asthma. ${ }^{43,44}$ Women are more likely to have ACOS than men. ${ }^{43}$ ACOS has been estimated to be present in $15 \%-45 \%$ of patients with obstructive airway disease, and the prevalence increases with age. ${ }^{44}$ Patients with ACOS have a high prevalence of mortality, frequent exacerbations, more severe attacks, and decreased pulmonary function when compared to those with asthma alone or COPD alone. ${ }^{45}$ They have also more comorbidities, such as diabetes mellitus and malignant disease. ${ }^{45,46}$ The most frequent cause of death in these patients is malignant disease. ${ }^{46}$ Distinguishing between asthma with a component of fixed airflow obstruction and COPD is important, especially in current and exsmokers. However, sometimes distinguishing clearly between asthma and COPD can be difficult. Reversibility of airway obstruction in elderly asthmatics is often reduced because of irreversible structural changes, and conversely, in patients with COPD, a significant response to bronchodilators can be observed. ${ }^{36,42}$ In addition to pulmonary function tests, assessment of inflammatory markers by induced sputum and the degree of airway remodeling by imaging methods might be useful to characterize patients with ACOS by phenotype. Other comorbidities such as malignant disease should also be evaluated in these patients. Little is known about the characteristics of these patients and how best to treat them. Different treatment options are recommended, such as symptom-based approaches and ACOS phenotyping-based approaches, for patients with ACOS. ${ }^{1,44,47}$

\section{Approaches to asthma phenotyping}

Widely accepted definitions of the phenotypes of severe allergic asthma in an elderly population are lacking. Lateonset asthma, early-onset asthma, corticosteroid insensitivity, and obesity characteristics can be helpful when considering specific therapies.

\section{Step 3: treatment \\ Nonpharmacologic interventions}

\section{Asthma education}

Considerable evidence suggests that patient education is very important for successful control of asthma. ${ }^{1}$ Adequate asthma education is particularly important in the elderly owing to the often complex treatments involved, comorbidities, and sometimes reduced memory and cognitive functions. ${ }^{4}$ Inappropriate methods for using inhaler devices are another problem in elderly patients with respect to uncontrolled disease. ${ }^{4}$ Recently, we found that older patients with asthma had limited knowledge of self-management and worse control of asthma and showed improper use of inhaler devices. Educational levels in these elderly patients were low; they did not use the Internet for asthma education, and the only source of asthma knowledge for such patients was physician-managed asthma care. ${ }^{16}$ Our study showed that standard asthma care is largely insufficient for older patients and that asthma education programs should be developed for older adults based on education level and asthma characteristics. Effective education programs for elderly patients with asthma would lower the prevalence of uncontrolled asthma in this population. ${ }^{16}$

\section{Controlling triggers}

Controlling triggers is the main step in the management of allergic asthma, but elderly asthmatics have little knowledge about asthma triggers. Wolfenden et $\mathrm{al}^{48}$ investigated factors associated with hospitalization and revealed that $40 \%$ of older people with asthma reported that they did not know everything they needed to know to manage flare ups, adjust their medications, or avoid asthma triggers. Weight-loss interventions and smoking cessation can also improve asthma outcomes. ${ }^{1}$ Vaccination against influenza and pneumococci is usually recommended in the elderly population. However, less evidence is available on the preventative role of influenza vaccination on asthma control in elderly patients with asthma. ${ }^{4}$ Pneumococcal vaccination is recommended in patients with COPD, but its value in adult patients with asthma is less certain. ${ }^{4}$

\section{Pharmacologic interventions}

Severe allergic asthma includes patients at steps 4 and 5 of GINA guidelines. ${ }^{1}$ General rules of pharmacotherapy for the 
elderly are not different from those for adult patients. ${ }^{1}$ GINA recommends add-on tiotropium if there is a history of exacerbation and a high-dose corticosteroid plus long-acting $\beta_{2}$ adrenergic agonist and extra controllers, such as leukotrienemodifying agents and theophylline for patients at step $4 .{ }^{1}$ Factors such as arthritis, inspiratory flow rate, and complexity of treatment regimens should be considered when choosing medication and inhaler devices. ${ }^{1}$ Treatment response must be monitored carefully because elderly patients may have discordant correlations between changes in symptoms and lung function. Side effects, polypharmacy, and drug interactions should also be considered in the elderly. ${ }^{49}$

Leukotriene-modifying agents have been shown to be effective in the prevention of allergen-induced asthma, but studies on their use in the elderly are limited. ${ }^{4}$ Inhaled $\beta$-agonists can induce tremor or tachycardia in susceptible patients. ${ }^{4}$ Tiotropium has an excellent safety profile in the elderly and may be a good option in age-related reduction in lung function and the frequent overlap between asthma and COPD in the elderly. ${ }^{4,49}$ Theophylline is an effective bronchodilator and has some anti-inflammatory properties, ${ }^{4}$ but its use has been reduced considerably over the past decade due to safety concerns, especially in the elderly. The narrow therapeutic range, frequency of concomitant illnesses that alter kinetics, and many drug interactions that affect the clearance of theophylline show that theophylline levels in the blood of elderly patients with asthma must be monitored closely. ${ }^{4}$ Anti$\operatorname{IgE}$ (omalixumab) is a treatment option for patients with severe allergic asthma uncontrolled upon step 4 treatment. ${ }^{1}$ Korn et a ${ }^{50}$ confirmed that the efficacy of omalixumab in patients with severe allergic asthma is similar in younger and older patients. Long-term treatment with oral corticosteroids may be required for some patients with severe allergic asthma. However, older individuals experience more adverse drug effects and have comorbidities such as diabetes mellitus and hypertension that can worsen because of corticosteroid use. Antiplatelet therapy with aspirin for the management of cerebrovascular disease or cardiovascular disease can be challenging in aspirin-sensitive patients with asthma. If aspirin therapy is indicated in an asthmatic patient with aspirin sensitivity, aspirin desensitization could be a treatment option. Key points in the management of severe allergic asthma are shown in Figure 2.

\section{Conclusion}

Some data suggest that allergic asthma in older adults is phenotypically different from that observed in younger patients. Asthma management in the elderly follows the same steps as that in younger adults, but asthma in the elderly is underdiagnosed and undertreated. Attending physicians must take into account the factors in elderly patients with

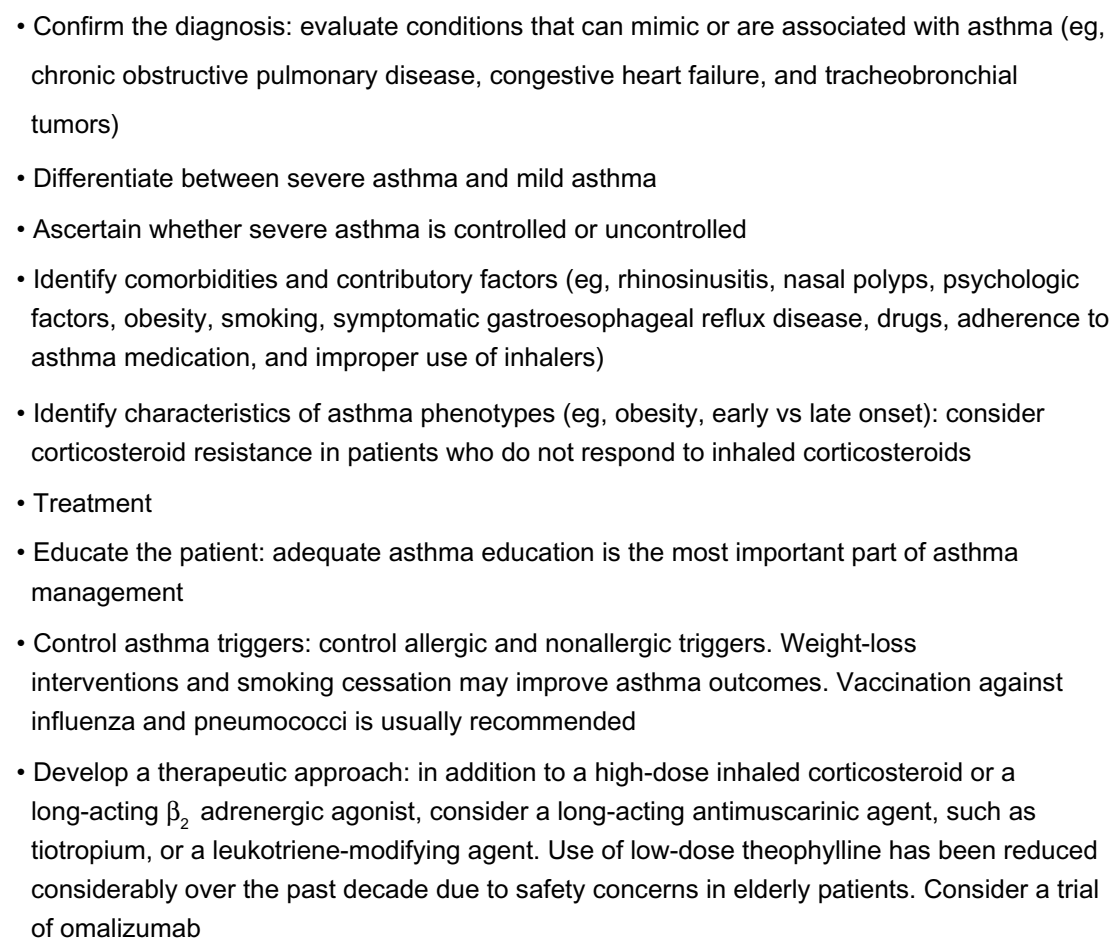

Figure 2 Key points in the management of severe allergic asthma. 
severe allergic asthma that contribute to the risk of uncontrolled disease: a low level of education; poor memory and coordination; hearing, visual, and neuromuscular difficulties in learning inhaler-use methods and asthma self-management plans; and nonadherence to asthma medication.

\section{Disclosure}

The authors report no conflicts of interest in this work.

\section{References}

1. Global Initiative for Asthma (GINA) [homepage on the internet]. Global Strategy for Asthma Management and Prevention. Available from: http:// www.ginasthma.org/local/uploads/files/GINA_Report_2015_Aug11. pdf. Accessed April 24, 2015.

2. de Nijs SB, Venekamp LN, Bel EH. Adult-onset asthma: is it really different? Eur Respir Rev. 2013;22:44-52.

3. Miranda C, Busacker A, Balzar S, Trudeau J, Wenzel SE. Distinguishing severe asthma phenotypes: role of age at onset and eosinophilic inflammation. J Allergy Clin Immunol. 2004;113:101-108.

4. Gibson PG, McDonald VM, Marks GB. Asthma in older adults. Lancet. 2010;376:803-813.

5. Yáñez A, Cho SH, Soriano JB, et al. Asthma in the elderly: what we know and what we have yet to know. World Allergy Organ J. 2014;7(1):8.

6. Bauer BA, Reed CE, Yunginger JW, Wollan PC, Silverstein MD. Incidence and outcomes of asthma in the elderly. A population-based study in Rochester, Minnesota. Chest. 1997;111(2):303-310.

7. Cardona V, Guilarte M, Luengo O, Labrador-Horrillo M, Sala-Cunill A, Garriga T. Allergic diseases in the elderly. Clin Transl Allergy. 2011;1:11.

8. Melani AS. Management of asthma in the elderly patient. Clin Interv Aging. 2013;8:913e922.

9. Di Lorenzo G, Di Bona D, La Piana S, Ditta V, Stefania Leto-Barone M. Bronchial asthma-emerging therapeutic strategies. In: Sapey E, editor. Allergic Asthma and Aging. Rijeka: InTech; 2012:90-116.

10. Ventura MT, Scichilone N, Gelardi M, Patella V, Ridolo E. Management of allergic disease in the elderly: key considerations, recommendations and emerging therapies. Expert Rev Clin Immunol. 2015;11(11):1219-1228.

11. Busse PJ, Cohn RD, Salo PM, Zeldin DC. Characteristics of allergic sensitization among asthmatic adults older than 55 years: results from the National Health and Nutrition Examination Survey, 2005-2006. Ann Allergy Asthma Immunol. 2013;110:247e252.

12. Jaakkola MS, Ieromnimon A, Jaakkola JJ. Are atopy and specific IgE to mites and molds important for adult asthma? J Allergy Clin Immunol. 2006;117:642e648.

13. Arruda LK, Vailes LD, Ferriani VP, Santos AB, Pomés A, Chapman MD. Cockroach allergens and asthma. J Allergy Clin Immunol. 2001;107: $419 \mathrm{e} 428$.

14. Di Lorenzo G, Mansueto P, Melluso M, et al. Non-specific airway hyperresponsiveness in mono-sensitive Sicilian patients with allergic rhinitis. Its relationship to total serum IgE levels and blood eosinophils during and out of the pollen season. Clin Exp. 1997;27(9): 1052-1059.

15. Celikel S, Isik SR, Demir AU, Karakaya G, Kalyoncu AF. Risk factors for asthma and other allergic diseases in seasonal rhinitis. J Asthma. 2008;45(8):710-714.

16. Ozturk AB, Ozyigit Pur L, Kostek O, Keskin H. Association between asthma self-management knowledge and asthma control in the elderly. Ann Allergy Asthma Immunol. 2015;114(6):480-484.

17. Wolfe R, Carlin JB, Oswald H, Olinsky A, Phelan PD, Robertson CF. Association between allergy and asthma from childhood to midadult life in an Australian cohort study. Am J Respir Crit Care Med. 2000;162:2177-2181.
18. Ozyigit Pur L, Ozturk AB, Keskin H. Allergic asthma: differences in characteristics between younger and older patients. Rev Fr Allergol. 2015;55(5):379-381.

19. Inoue H, Niimi A, Takeda T, et al. Pathophysiological characteristics of asthma in the elderly: a comprehensive study. Ann Allergy Asthma Immunol. 2014;113(5):527-533.

20. Braman SS, Kaemmerlen JT, Davis SM. Asthma in the elderly. A comparison between patients with recently acquired and long-standing disease. Am Rev Respir Dis. 1991;143(2):336-340.

21. Enright PL, Ward BJ, Tracy RP, Lasser EC. Asthma and its association with cardiovascular disease in the elderly. The Cardiovascular Health Study Research Group. J Asthma. 1996;33(1):45-53.

22. Park HW, Kwon HS, Kim TB, et al; COREA Study Group. Differences between asthma in young and elderly: results from the COREA study. Respir Med. 2013;107:1509-1514.

23. Park HW, Song WJ, Kim SH, et al. Classification and implementation of asthma phenotypes in elderly patients. Ann Allergy Asthma Immunol. 2015;114(1):18-22.

24. Tsai C-L, Lee W-Y, Hanania N, Camargo CA Jr. Age-related differences in clinical outcomes for acute asthma in the United States, 2006-2008. J Allergy Clin Immunol. 2012;7:152-158.

25. Talreja N, Baptist AP. Effect of age on asthma control: results from the National Asthma Survey. Ann Allergy Asthma Immunol. 2011;106:24e29.

26. Chung KF, Wenzel SE, Brozek JL, et al. International ERS/ATS guidelines on definition, evaluation and treatment of severe asthma. Eur Respir J. 2014;43:343-373.

27. Hanania NA, King MJ, Braman SS, et al; Ledford DK; Asthma in Elderly Workshop Participants. Asthma in the elderly: current understanding and future research needs - a report of a National Institute on Aging (NIA) workshop. J Allergy Clin Immunol. 2011;128(3 suppl): S4-S24.

28. Mathur SK. Allergy and asthma in the elderly. Semin Respir Crit Care Med. 2010;31(5):587-595.

29. Reed CE. Asthma in the elderly: diagnosis and management. J Allergy Clin Immunol. 2010;126:681-687.

30. Milanese M, Di Marco F, Corsico AG, et al; ELSA Study Group. Asthma control in elderly asthmatics. An Italian observational study. Respir Med. 2014;108(8):1091-1099.

31. Goeman DP, Douglas JA. Optimal management of asthma in elderly patients. Starategies to improve adherence to recommended interventions. Drugs Aging. 2007;24(5):381-391.

32. Yap AF, Thirimoorthy T, Kwan YH. Systematic review of the barriers affecting medication adherence in older adults. Geriatr Gerontol Int. Epub 2015 Oct 20.

33. Moore WC, Bleecker ER, Curran-Everett D, et al; National Heart, Lung, Blood Institute's Severe Asthma Research Program. Characterization of the severe asthma phenotype by the National Heart, Lung, and Blood Institute's Severe Asthma Research Program. J Allergy Clin Immunol. 2007;119:405-413.

34. Moore WC, Meyers DA, Wenzel SE, et al; National Heart, Lung, and Blood Institute's Severe Asthma Research Program. Identification of asthma phenotypes using cluster analysis in the Severe Asthma Research Program. Am J Respir Crit Care Med. 2010;181:315-323.

35. Wardzyńska A, Kubsik B, Kowalski ML. Comorbidities in elderly patients with asthma: association with control of the disease and concomitant treatment. Geriatr Gerontol Int. 2015;15(7):902-909.

36. National Heart, Lung, and Blood Institute [webpage on the Internet]. NAEPP Working Group Report. Considerations for Diagnosing and Managing Asthma in the Elderly. Available from: http://msdh.ms.gov/ msdhsite/_static/resources/2107.pdf. Accessed March 20, 2013.

37. Chen MH, Li CT, Tsai CF, et al. Risk of dementia among patients with asthma: a nationwide longitudinal study. J Am Med Dir Assoc. 2014;15(10):763-767.

38. Bozek A, Jarzab J. Improved activity and mental function related to proper antiasthmatic treatment in elderly patients with Alzheimer's disease. Allergy Asthma Proc. 2011;32(5):341-345. 
39. Soriano JB, Visick GT, Muellerova H, Payvandi N, Hansell AL. Patterns of comorbidities in newly diagnosed COPD and asthma in primary care. Chest. 2005;7:2099-2107.

40. Manouchehrinia A, Edwards LJ, Roshanisefat H, Tench CR, Constantinescu CS. Multiple sclerosis course and clinical outcomes in patients with comorbid asthma: a survey study. BMJ Open. 2015;5(5):e007806.

41. Cheng CM, Wu YH, Tsai SJ, et al. Risk of developing Parkinson's disease among patients with asthma: a nationwide longitudinal study. Allergy. 2015;70(12):1605-1612.

42. Global Initiative for Chronic Obstructive Lung Disease [webpage on the Internet]. Global Strategy for the Diagnosis, Management, and Prevention of Chronic Obstructive Pulmonary Disease [updated April 2, 2015]. Avaliable from: http://www.goldcopd.org/uploads/users/files/ GOLD_Report_2015_Apr2.pdf. Accessed January 30, 2016.

43. De Marco R, Pesce G, Macron A, et al. The coexistence of asthma and chronic obstructive pulmonary disease (COPD): prevalence and risk factors in young, middle aged and elderly people from the general population. PLoS One. 2013;8(5):e62985.
44. Postma DS, Rabe KF. The asthma-COPD overlap syndrome. $N$ Engl J Med. 2015;373(13):1241-1249.

45. Nielsen M, Barnes CB, Ulrich CS. Clinical characteristics of the asthmaCOPD overlap syndrome-a systemic review. Int J Chron Obstruct Pulmon Dis. 2015;10:1443-1454.

46. Harata T, Yamasaki A, Fukishima T, et al. Causes of death in patient with asthma and asthma-chronic obstructive pulmonary disease overlap syndrome. Int J Chron Obstruct Pulmon Dis. 2015;10:595-602.

47. Barnes PJ. Therapeutic approaches to asthma-chronic obstructive pulmonary disease overlap syndrome. J Allergy Clin Immunol. 2015;136:531-545.

48. Wolfenden LL, Diette GB, Skinner EA, Steinwachs DM, Wu AW. Gaps in asthma care of the oldest adults. J Am Geriatr Soc. 2002;50: 877-883.

49. Song WJ, Cho SH. Challenges in management of asthma in the elderly. Allergy Asthma Immunol Res. 2015;7(5):431-439.

50. Korn S, Schumann C, Kropf C, et al. Effectiveness of omalizumab in patients 50 years and older with severe persistent allergic asthma. Ann Allergy Asthma Immunol. 2010;105(4):313-319.

\section{Publish your work in this journal}

The Journal of Asthma and Allergy is an international, peer-reviewed open-access journal publishing original research, reports, editorials and commentaries on the following topics: Asthma; Pulmonary physiology; Asthma related clinical health; Clinical immunology and the immunological basis of disease; Pharmacological interventions and

\section{Dovepress}

new therapies. Issues of patient safety and quality of care will also be considered. The manuscript management system is completely online and includes a very quick and fair peer-review system, which is all easy to use. Visit http://www.dovepress.com/testimonials.php to read real quotes from published authors. 